\title{
Histological Comparison of Fibrous Root Infection of Disease-Tolerant and Susceptible Citrus Hosts by Phytophthora nicotianae and P. palmivora
}

\author{
T. L. Widmer, J. H. Graham, and D. J. Mitchell
}

First and third authors: Department of Plant Pathology, University of Florida, IFAS, Gainesville 32611; and second author: Citrus Research and Education Center, University of Florida, Institute of Food and Agricultural Sciences, 700 Experiment Station Road, Lake Alfred 33850. Accepted for publication 9 February 1998

\begin{abstract}
Widmer, T. L., Graham, J. H., and Mitchell, D. J. 1998. Histological comparison of fibrous root infection of disease-tolerant and susceptible citrus hosts by Phytophthora nicotianae and P. palmivora. Phytopathology 88:389-395.

Phytophthora nicotianae and P. palmivora infect and cause rot of fibrous roots of susceptible and tolerant citrus rootstocks in Florida orchards. The infection and colonization by the two Phytophthora spp. of a susceptible citrus host, sour orange (Citrus aurantium), and a tolerant host, trifoliate orange (Poncirus trifoliata), were compared using light and electron microscopy. Penetration by both Phytophthora spp. occurred within $1 \mathrm{~h}$ after inoculation, regardless of the host species. No differences were observed in mode of penetration of the hypodermis or the hosts' response to infection. After $24 \mathrm{~h}, P$. palmivora had a significantly higher colonization of cortical cells in susceptible sour orange than in tolerant trifoliate orange. Intracellular hyphae of both Phytophthora spp. were observed in the cortex
\end{abstract}

ABSTRACT of sour orange, and cortical cells adjacent to intercellular hyphae of $P$. palmivora were disrupted. In contrast, the cortical cells of sour orange and trifoliate orange adjacent to P. nicotianae hyphae and the cortical cells of trifoliate orange adjacent to $P$. palmivora were still intact. After $48 \mathrm{~h}$, the cortical cells of both hosts adjacent to either Phytophthora spp. were disrupted. After 48 and $72 \mathrm{~h}$, P. palmivora hyphae colonized the cortex of sour orange more extensively than the cortex of trifoliate orange; $P$. palmivora also colonized both hosts more extensively than $P$. nicotianae. A higher rate of electrolyte leakage among host-pathogen combinations reflected the combined effects of greater cell disruption by $P$. palmivora than by $P$. nicotianae, and the higher concentration of electrolytes in healthy roots of trifoliate orange than of sour orange. Although cellular responses unique to the tolerant host were not observed, reduced hyphal colonization by both pathogens in the cortex of trifoliate orange compared with sour orange is evidence for a putative resistance factor(s) in the trifoliate orange roots that inhibits the growth of Phytophthora spp.
In Florida citrus orchards, Phytophthora nicotianae Breda de Haan (synonym $=P$. parasitica Dastur) causes a fibrous root rot on tolerant as well as susceptible rootstocks $(13,20)$. Although the epidemiology of the pathogen and losses caused by this disease have been evaluated extensively $(9,13,20,29)$, these studies provide only indirect information on differences in the infection progress in roots of tolerant and susceptible hosts. Comparisons of several citrus rootstocks in the greenhouse and field demonstrated that infection of young roots occurs very rapidly and at the same rate on susceptible and tolerant hosts, but that root rot damage and fungal reproduction are limited subsequently on tolerant hosts (13, 20). Citrus rootstocks are generally referred to as tolerant rather than resistant, because fibrous roots become infected. Graham (12) defined tolerance, as applies to citrus rootstocks, as the condition in which plants are infected but show little or no net root loss. Tolerance was furthermore identified as the capability to regenerate roots to a greater extent in the presence of the pathogen than in the absence compared with susceptible rootstocks (13). In this study of citrus rootstocks, tolerance is used in this context.

In the late 1980s and 1990s, P. palmivora (E. J. Butler) E. J. Butler was identified and found to be highly pathogenic on the root system in Florida citrus orchards (44, J. H. Graham, unpublished data). In a greenhouse study, Zitko and Timmer (44) showed that $P$. palmivora was a more aggressive and damaging pathogen than $P$. nicotianae on certain Citrus spp. Although the competitive

Corresponding author: J. H. Graham; E-mail address: jhg@ @icon.lal.ufl.edu

Publication no. P-1998-0320-01R

(c) 1998 The American Phytopathological Society nature of the two pathogens coinfecting the roots of susceptible citrus rootstocks was evaluated, differential infection of susceptible and tolerant hosts was not considered.

Ultrastructural studies of other pathosystems involving the interaction of Phytophthora spp. with resistant and susceptible hosts indicate that encysted zoospores rapidly form germ tubes that penetrate through the periclinal wall or, in the majority of cases, through the middle lamella of the anticlinal walls of root epidermal cells $(16,26,37)$. Alterations of the middle-lamella matrices without major deformation of penetrated primary cell walls support the idea that root invasion by some Phytophthora spp. is achieved primarily by enzymatic means rather than by mechanical means $(3,36)$. After initial penetration events, differences in cellular responses depend upon the host's susceptibility or resistance to the pathogen $(6,11$, 38). For example, Cahill et al. (6) showed that lignification of cell walls, deposition of phenolics, and formation of callosic papillae were more common in incompatible systems involving $P$. cinnamomi than in compatible systems.

We sought to determine if trifoliate orange (Poncirus trifoliata L. selection 50-7), currently defined as highly tolerant, displays resistance reactions such as hypersensitivity, necrosis of the fungal hyphae during the penetration process, reduced rate of fungal ingress and cell disruption, or possibly other responses in contrast with the susceptible rootstock, sour orange (Citrus aurantium L.). Early infection processes of $P$. nicotianae and $P$. palmivora on susceptible sour orange and tolerant trifoliate orange roots were studied using light and electron microscopy for up to $168 \mathrm{~h}$ after inoculation. As an independent evaluation of the host-pathogen interactions, such as cellular disruption and hypersensitivity (if observed), the rate of electrolyte leakage from zoospore-inoculated root tips was measured during the initial stages of infection. We 
expected that insights into the infection process and the host's response at the cellular level would lead to a better understanding of the mechanisms involved in tolerance and resistance of citrus rootstocks to Phytophthora diseases and, eventually, new ideas for plant protection.

\section{MATERIALS AND METHODS}

Media and soil preparation. Strains of $P$. nicotianae and $P$. palmivora used in this study were isolated from citrus rhizosphere soil (23). They were maintained on clarified V-8 juice (Campbell Soup Co., Camden, NJ) agar at $18^{\circ} \mathrm{C}$ in the dark (30).

Candler fine sand (uncoated, hyperthermic, Typic Quartzipsamments), collected near Davenport, FL, was pasteurized by microwaving $1 \mathrm{~kg}$ of moist soil (approximately 7\% wt/wt moisture) for 4 min in an 800-watt microwave oven $(10,41)$. The soil was cooled to room temperature prior to use.

Zoospore production. Zoospores of $P$. nicotianae and $P$. palmivora were produced by a modified procedure of Mitchell and Kannwischer-Mitchell (23). Four 5-mm disks from V-8 agar cultures of $P$. nicotianae or $P$. palmivora were dispensed into each of three petri plates containing $15 \mathrm{ml}$ of sterile, half-strength $\mathrm{V}-8$ broth. Cultures were grown for 3 days in the dark in an incubator at $25^{\circ} \mathrm{C}$. The liquid medium was aseptically removed with a pipette, and the mycelium was washed three times with sterile, distilled water. Mycelium was resuspended in sterile, distilled water and placed under direct, continuous, artificial light for 3 days at room temperature to induce sporangium formation. After chilling for $30 \mathrm{~min}$ at $4^{\circ} \mathrm{C}$, the cultures were placed at room temperature until sporangia released zoospores. The zoospores were carefully separated from the mycelium by slowly pouring the suspension into a beaker, and an equal volume of sterile, distilled water was added to the zoospore suspension. The active zoospores were counted by pipetting $1 \mu 1$ onto a glass slide and observing them under a microscope.

Plant inoculations. Five-week-old seedlings of sour orange and trifoliate orange were carefully removed from Metro-Mix 500 growth medium (The Scotts Co., Marysville, OH). Seedlings with

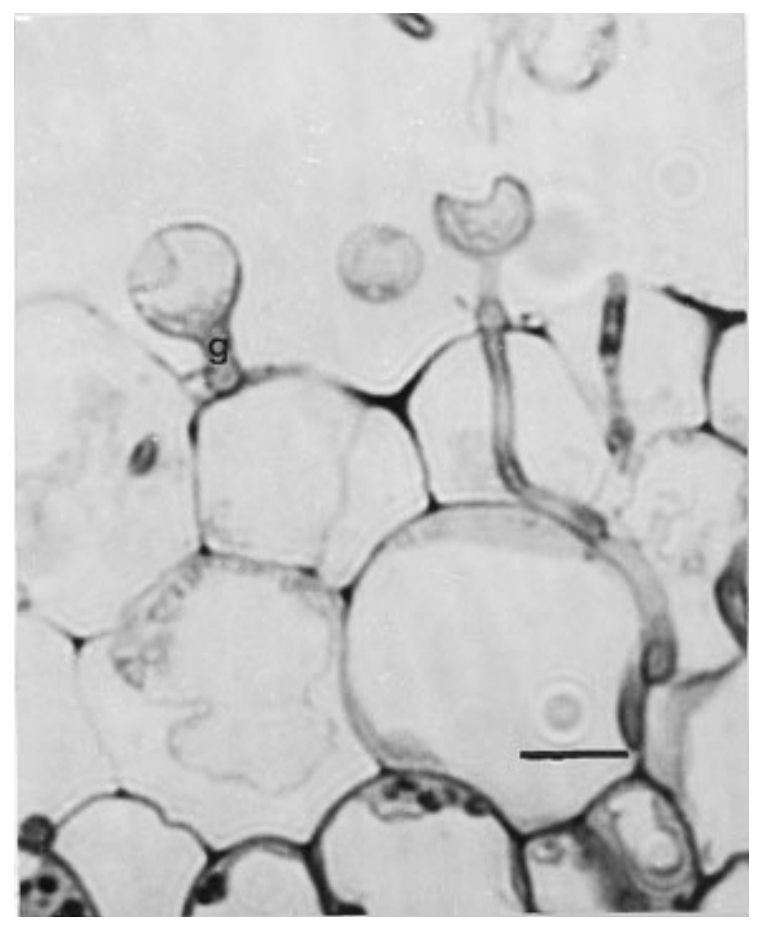

Fig. 1. Prepenetration and initial penetration stages through the periclinal walls of the hypodermis of roots of tolerant trifoliate orange (Poncirus trifoliata) $4 \mathrm{~h}$ after inoculation with Phytophthora nicotianae zoospores. Bar $=$ $20 \mu \mathrm{m}$, and $\mathrm{g}=$ germ tube. white, healthy root tips were laid on top of a layer of pasteurized soil in a large petri dish $(150$ by $15 \mathrm{~mm})$. Small Parafilm (American National Can, Neenah, WI) wells were made by molding the Parafilm in a depression. These wells were placed under the root tips. Sterile water was pipetted into the wells to cover approximately $10 \mathrm{~mm}$ of the root tip. A spore suspension containing approximately 1,000 active zoospores was pipetted into each well. The remaining root system, which was not inoculated, was covered with pasteurized soil. The petri plates were covered and placed in an incubator at $27^{\circ} \mathrm{C}$ in the dark.

Light and electron microscopy. After 1, 2, 4, 24, 48, 72, and $168 \mathrm{~h}$, inoculated roots were excised from the root system just above the point where the zoospore solution covered the root. Three root tips were sampled for each time period, for each host, and for each Phytophthora sp. The samples were fixed in 3\% glutaraldehyde in $0.05 \mathrm{M}$ cacodylate buffer at $\mathrm{pH} 7.2$ overnight at $4{ }^{\circ} \mathrm{C}$ and then washed twice in the same buffer. The samples were treated in $2 \%$ $\mathrm{OsO}_{4}$ for $3 \mathrm{~h}$ at room temperature. After washing twice in the buffer, the samples were dehydrated in a graded series of acetone $(10,20$, $30,40,50,60,70,80,90$, and $100 \%$ ) for $10 \mathrm{~min}$ in each wash. The samples were washed three times in $100 \%$ acetone. The root samples were infiltrated with Spurr's resin (8) by maintaining them for $1 \mathrm{~h}$ at room temperature in a mixture of $30 \%$ resin and $70 \%$ acetone, for $4 \mathrm{~h}$ in a mixture of $50 \%$ resin and $50 \%$ acetone, and then overnight in a mixture of $70 \%$ resin and $30 \%$ acetone. After an additional $8 \mathrm{~h}$ in $100 \%$ resin, the samples were placed in molds, covered with fresh plastic, and placed in an oven at $70^{\circ} \mathrm{C}$ overnight.

Thick sections $(1 \mu \mathrm{m})$ were cut with a glass knife mounted in an ultra-microtome (LKB Instruments, Bromma, Sweden). The sections were mounted on a glass slide by heating, stained with a solution of methylene blue-azure A, and counter-stained with a solution of basic fuchsin for light microscopy (18). Ultrathin sections (8) were cut with a glass knife using the ultra-microtome, mounted on a 200-mesh, Formvar-coated copper grid, and stained with uranyl acetate (32) and lead citrate (27). Ultrathin sections were observed with a Philips 201 transmission electron microscope (Philips Scientific, Eindhoven, the Netherlands).

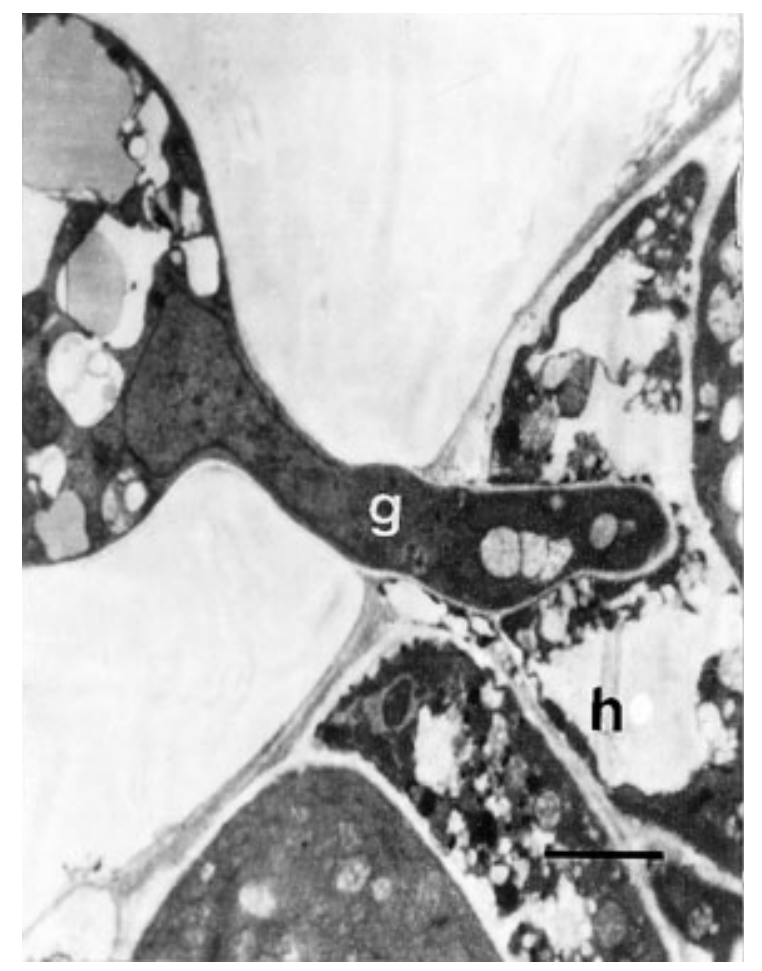

Fig. 2. Electron micrograph of a germ tube from an encysted zoospore of Phytophthora palmivora penetrating a hypodermal cell of susceptible sour orange (Citrus aurantium) $1 \mathrm{~h}$ after inoculation of roots with motile zoospores. Bar $=2 \mu \mathrm{m}, \mathrm{g}=$ germ tube, and $\mathrm{h}=$ host cell. 
Colonization of roots was measured by observing thick crosssections of stained roots at approximately $5 \mathrm{~mm}$ from the root tip. Three sections from each of three different roots were examined. Colonization was rated on a scale of 0 to 9 . A rating of 0 was given for 0 hyphae per section (hps), 1 for 1 to $10 \mathrm{hps}, 2$ for 11 to $25 \mathrm{hps}, 3$ for 26 to $40 \mathrm{hps}, 4$ for 41 to $50 \mathrm{hps}, 5$ for 51 to $75 \mathrm{hps}, 6$ for 76 to $90 \mathrm{hps}, 7$ for 91 to $125 \mathrm{hps}, 8$ for 126 to $175 \mathrm{hps}$, and 9 for more than $175 \mathrm{hps}$. The experiment was conducted two times with similar results. The results of one experiment are presented. Data from each experiment were subjected to the general linear model (GLM) procedure for analysis of variance (SAS Institute, Cary, NC), and mean separations of colonization ratings at each sampling time were made using least significant differences and Student's paired $t$ tests.

Electrolyte leakage. Experiments were set up following a modified procedure of Zilberstein and Pinkas (42). Healthy, white root tips of 5-week-old sour orange (susceptible) and trifoliate orange 50-7 (tolerant) seedlings were cut $15 \mathrm{~mm}$ from the root tip. The root tips were washed three times in sterile, double-distilled water to remove any residual electrolytes. Ten root tips each of sour orange or trifoliate orange were placed in a single petri plate $(60$ by $15 \mathrm{~mm}$ ) containing $10 \mathrm{ml}$ of sterile, double-distilled water. One thousand zoospores of either $P$. nicotianae or $P$. palmivora were added to each of five petri plates containing root tips. Controls were also prepared with no zoospore inoculations. The root tips were placed in an incubator at $27^{\circ} \mathrm{C}$, and the conductivity of the
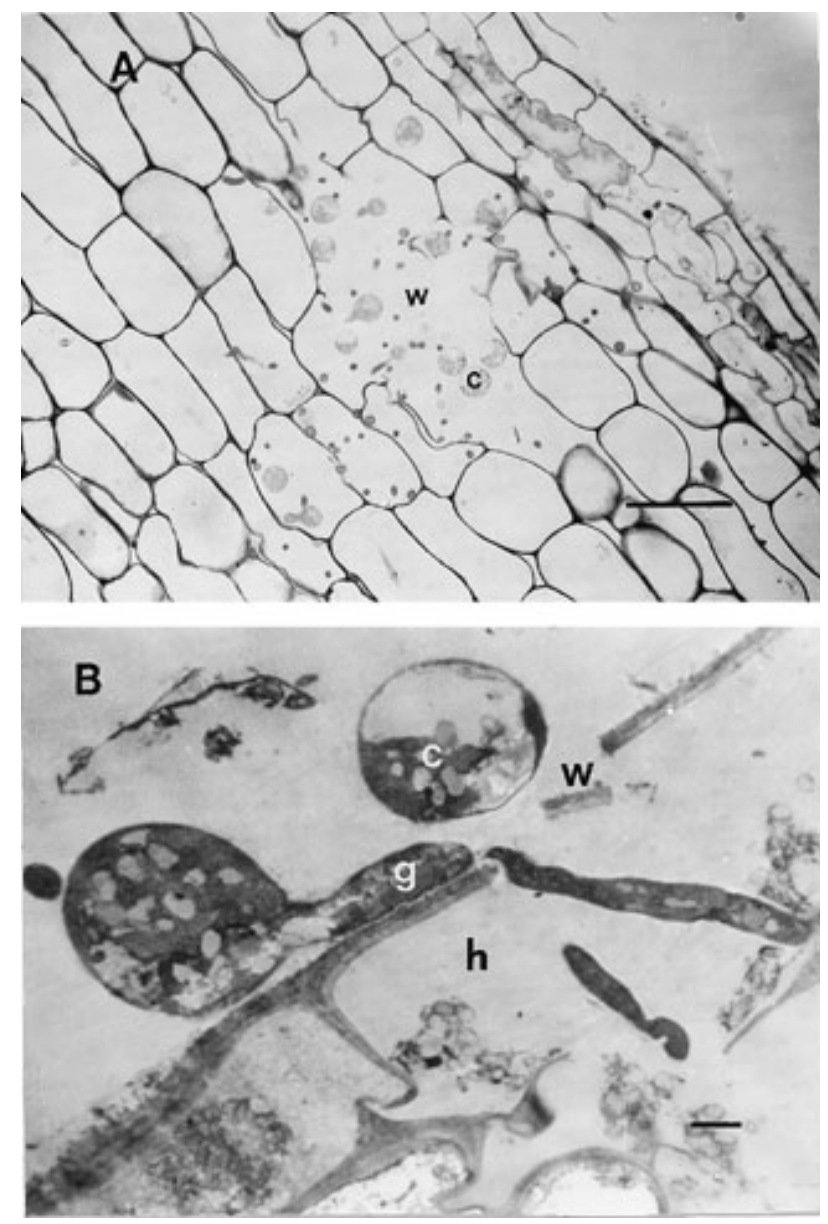

Fig. 3. Attraction and germination of encysted zoospores of Phytophthora palmivora at a natural wound site on a root of tolerant trifoliate orange (Poncirus trifoliata) $2 \mathrm{~h}$ after inoculation. $\mathrm{c}=$ encysted zoospore, $\mathrm{g}=$ germ tube, $\mathrm{h}=$ host cell, and $\mathrm{w}=$ wound site. $\mathbf{A}$, Light micrograph showing accumulation and encystment of zoospores at the wound site. Bar $=100 \mu \mathrm{m}$. B, Electron micrograph of a germ tube from an encysted zoospore entering a wound site. Bar $=2 \mu \mathrm{m}$. solution ( $\mu \mathrm{S} / 0.1 \mathrm{~g}$ of fresh tissue) was measured every $12 \mathrm{~h}$ up to $108 \mathrm{~h}$ using an ElectroMark analyzer (Markson Science, Inc., Mara, CA). The conductivity of the noninoculated control was subtracted from the conductivity of the inoculated treatment to give the final conductivity value for that time period. After the last measurement, the root tips were surface-sterilized for $10 \mathrm{~s}$ in $70 \%$ ethanol, rinsed twice in sterile, deionized water, and plated on a medium selective for the isolation of Phytophthora spp. to confirm infection (pimaricin-ampicillin-rifampicin-pentachloronitrobenzene-hymexazol [PARPH]) (23).

Electrolyte content of healthy roots of each host was evaluated similarly. Ten healthy, white-tipped roots of sour orange or trifoliate orange were cut into $15-\mathrm{mm}$ sections, weighed, and placed in each of three test tubes. The root tips were washed three times in sterile, double-distilled water. After the final rinse, $10 \mathrm{ml}$ of doubledistilled water was added. The suspension was transferred to a tissue grinder and the roots were macerated until no visible segments were observed. Electrical conductivity of the suspension was measured immediately.

The experiments with inoculated and noninoculated roots were repeated with similar results, and the results of one of the experiments are reported. Data from each experiment were subjected to the GLM procedure for analysis of variance (SAS Institute) and mean separations of electrolyte leakage at each sampling period made using least significant differences.

\section{RESULTS}

Light and electron microscopy. Zoospores of either $P$. nicotianae or $P$. palmivora germinated and penetrated the hypodermal cells of both susceptible sour orange and tolerant trifoliate orange roots within $1 \mathrm{~h}$ after inoculation. Germ tubes from encysted zoospores appeared swollen at the site of cell wall contact (Fig. 1). Penetration through the periclinal wall of the hypodermal cell or through the middle lamella of the anticlinal wall was observed in all treatments and did not vary between host or Phytophthora species. After initial penetration of the hosts' cell walls, the swelling of the germ tube persisted (Fig. 2). Zoospores were also attracted and germinated at sites of natural wounds on the root (Fig. 3). Germ tubes penetrated these sites after $2 \mathrm{~h}$.

At $24 \mathrm{~h}$ after inoculation, hyphae of $P$. nicotianae and $P$. palmivora colonized the cortical cells as deeply as the third layer (of a total of 8 to 10 cell layers) in trifoliate orange. The cortex of sour orange was penetrated by $P$. nicotianae more deeply than that of trifoliate orange. Hyphae of P. palmivora were observed to colonize the stele of sour orange after $24 \mathrm{~h}$. In trifoliate orange, hyphae of $P$. nicotianae and $P$. palmivora were confined to the intercellular spaces. $P$. palmivora had a significantly higher colonization rating in sour orange than the colonization ratings for either $P$. palmivora or $P$. nicotianae on trifoliate orange (Table 1). The percentage of hy-

TABLE 1. Colonization of the root cortex by hyphae of Phytophthora spp. at 24,48 , and $72 \mathrm{~h}$ after zoospore inoculation of susceptible sour orange (Citrus aurantium) and tolerant trifoliate orange (Poncirus trifoliata)

\begin{tabular}{lllll}
\hline & & \multicolumn{3}{c}{ Colonization rating } \\
\cline { 3 - 5 } Phytophthora sp. & Host species & $24 \mathrm{~h}^{\mathrm{y}}$ & $48 \mathrm{~h}$ & $72 \mathrm{~h}$ \\
\hline P. palmivora & Sour orange & $2.8 \mathrm{a}^{\mathrm{z}}$ & $8.2 \mathrm{a}$ & $7.9 \mathrm{a}$ \\
P. nicotianae & Sour orange & $1.5 \mathrm{ab}$ & $4.2 \mathrm{~b}$ & $6.4 \mathrm{~b}$ \\
P. palmivora & Trifoliate orange & $1.0 \mathrm{~b}$ & $4.7 \mathrm{~b}$ & $6.7 \mathrm{~b}$ \\
P. nicotianae & Trifoliate orange & $0.4 \mathrm{~b}$ & $3.0 \mathrm{~b}$ & $4.5 \mathrm{c}$ \\
\hline
\end{tabular}

${ }^{x}$ Average rating of three sections from each of three different roots based upon the following scale: $0=0$ hyphae per section (hps); $1=1$ to $10 \mathrm{hps} ; 2$ $=11$ to $25 \mathrm{hps} ; 3=26$ to $40 \mathrm{hps} ; 4=41$ to $50 \mathrm{hps} ; 5=51$ to $75 \mathrm{hps} ; 6=76$ to $90 \mathrm{hps} ; 7=91$ to $125 \mathrm{hps} ; 8=126$ to $175 \mathrm{hps}$; and $9=>175 \mathrm{hps}$.

y Time sampled after inoculation with zoospores of Phytophthora spp.

${ }^{\mathrm{z}}$ Means within the same column followed by the same letter are not significantly different $(P \leq 0.05)$ according to least significant differences. 
phae that were intracellular in the cortex was higher at 24 and $72 \mathrm{~h}$ in the $P$. palmivora-sour orange pathosystem than in the other pathosystems (Table 2). At $48 \mathrm{~h}$, the percentage of intracellular hyphae was lower for $P$. nicotianae in trifoliate orange than in sour orange.

At $24 \mathrm{~h}$ after inoculation, cortical cells of sour orange, adjacent to the intercellular P. palmivora hyphae, were disrupted (Fig. 4A). The plasma membrane had collapsed and no organelles were observed in the cell lumen. The middle lamella was more pronounced and stained darker with $\mathrm{OsO}_{4}$. At the same period after inoculation, the cortical cells of sour orange and trifoliate orange adjacent to the intercellular $P$. nicotianae hyphae and the cortical cells of trifoliate orange adjacent to the intercellular $P$. palmivora hyphae were intact (Fig. 4B).

At $48 \mathrm{~h}$ from inoculation, hyphae had grown into the stele in all treatments. Cortical cells were disrupted adjacent to hyphae of $P$. nicotianae and $P$. palmivora in the intercellular spaces at $48 \mathrm{~h}$ after inoculation and later time intervals (data not shown) (40). This was observed for both hosts.

Intra- and intercellular colonization of roots for both pathosystems was even more extensive at $72 \mathrm{~h}$ (Tables 1 and 2) and $168 \mathrm{~h}$ after inoculation. The colonization ratings for both Phytophthora spp. examined separately were significantly higher $(P \leq 0.01)$ in sour orange than in trifoliate orange after $72 \mathrm{~h}$ (Table 1$)$.

At 24 and $72 \mathrm{~h}$ after inoculation, colonization of the cortex of sour orange by the two Phytophthora spp. (data combined) was significantly greater than the colonization of trifoliate orange (Fig. 5). There were higher percentages of intracellular hyphae in sour orange than in trifoliate orange at all times measured. $P$. palmivora had a higher colonization rating than $P$. nicotianae after 48 and $72 \mathrm{~h}$ when ratings for both hosts were combined. P. palmivora had a significantly higher percentage of intracellular hyphae at 24 and $72 \mathrm{~h}$ after inoculation.

Electrolyte leakage. There was no electrolyte leakage detected from the infected roots until $12 \mathrm{~h}$ after inoculation in any of the treatments (Fig. 6). After 24 h, only the P. palmivora-sour orange pathosystem had a significantly higher conductivity than the noninoculated controls (data not shown). No measurable electrolyte leakage occurred in trifoliate orange inoculated with $P$. nicotianae until after $48 \mathrm{~h}$. Rate of electrolyte leakage from trifoliate orange roots infected with $P$. palmivora was significantly greater than from all other host-pathogen combinations at $72 \mathrm{~h}$. After $108 \mathrm{~h}$, the electrolyte leakage of sour orange or trifoliate orange inoculated with $P$. palmivora was significantly higher than the same hosts inoculated with $P$. nicotianae. At the completion of the study, there was no significant difference in the colonization frequency of the root tips as detected on PARPH selective medium $(P \leq 0.05)$. Average electrical conductivity per $0.1 \mathrm{~g}$ of roots was greater for macerated, noninoculated root tips of trifoliate orange $(182 \mu \mathrm{S})$ than for tips of sour orange $(148 \mu \mathrm{S}$; $P \leq 0.05)$.

TABLE 2. Percentage of total number of hyphae of Phytophthora spp. in the root cortex that was intracellular at 24,48 , and $72 \mathrm{~h}$ after zoospore inoculation of susceptible sour orange (Citrus aurantium) and tolerant trifoliate orange (Poncirus trifoliata)

\begin{tabular}{llccc}
\hline & & \multicolumn{3}{c}{ Intracellular hyphae $(\%)^{\mathrm{x}}$} \\
\cline { 3 - 5 } Phytophthora sp. & Host species & $24 \mathrm{~h}^{\mathrm{y}}$ & $48 \mathrm{~h}$ & $72 \mathrm{~h}$ \\
\hline P. palmivora & Sour orange & $14.2 \mathrm{a}^{\mathrm{z}}$ & $21.7 \mathrm{a}$ & $44.0 \mathrm{a}$ \\
P. nicotianae & Sour orange & $0.9 \mathrm{~b}$ & $24.4 \mathrm{a}$ & $27.9 \mathrm{~b}$ \\
P. palmivora & Trifoliate orange & $0.0 \mathrm{~b}$ & $15.1 \mathrm{ab}$ & $18.1 \mathrm{~b}$ \\
P. nicotianae & Trifoliate orange & $0.0 \mathrm{~b}$ & $8.5 \mathrm{~b}$ & $18.3 \mathrm{~b}$ \\
\hline
\end{tabular}

${ }^{\mathrm{x}}$ Mean of the percentage of total number of hyphae observed that were intracellular.

y Time sampled after inoculation with zoospores of Phytophthora spp.

${ }^{z}$ Means within the same column followed by the same letter are not significantly different $(P \leq 0.05)$ according to least significant differences.

\section{DISCUSSION}

Zoospores of $P$. nicotianae and $P$. palmivora encysted, germinated, and penetrated the hypodermal cells of tolerant and susceptible citrus hosts during the same time period and in the same manner. The penetration of roots by both Phytophthora spp. occurred within $2 \mathrm{~h}$, confirming observations of other Phytophthora pathosystems $(6,7,15,16,38)$. Zoospores were attracted to natural wounds on roots of tolerant and susceptible rootstocks alike, where

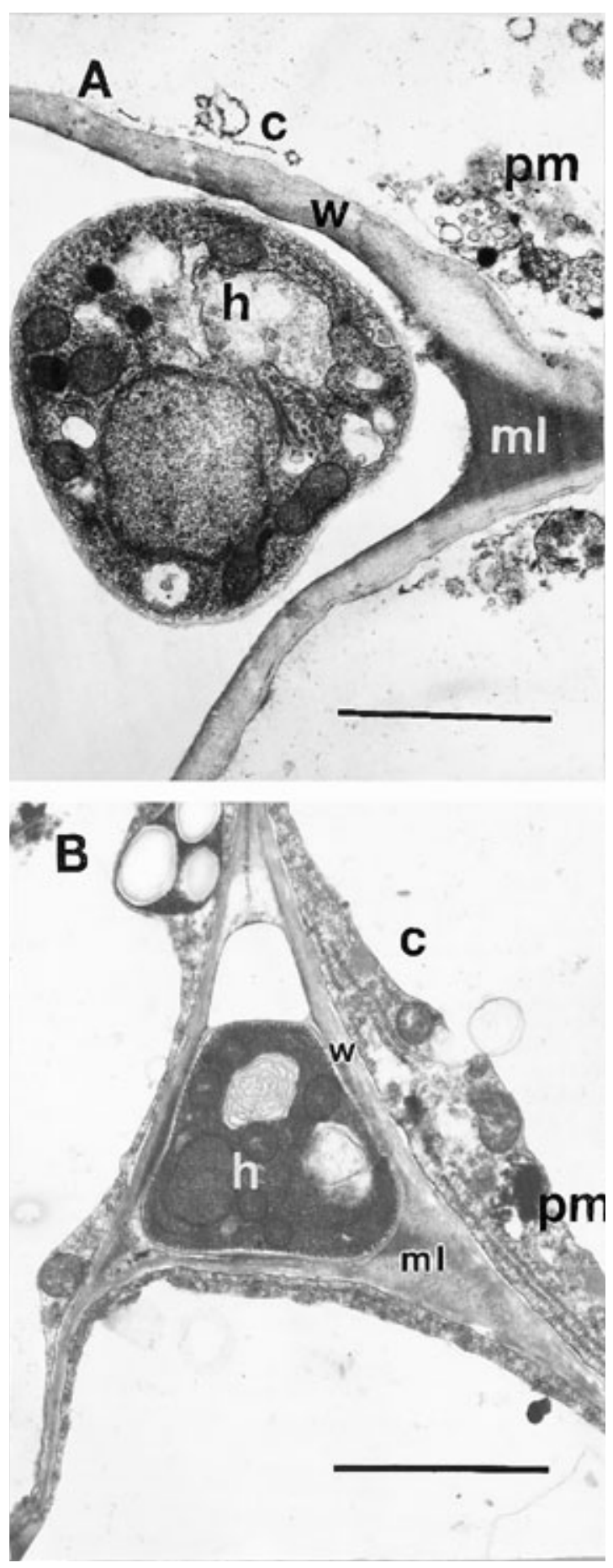

Fig. 4. Electron micrographs of intercellular hyphae of Phytophthora palmivora and the effect on adjacent cortical cells of susceptible sour orange (Citrus aurantium) and tolerant trifoliate orange (Poncirus trifoliata) $24 \mathrm{~h}$ after inoculation of roots. Bar $=2 \mu \mathrm{m}, \mathrm{c}=$ cortical cell, $\mathrm{h}=$ hypha, $\mathrm{ml}=$ middle lamella, $\mathrm{pm}=$ plasma membrane , and $\mathrm{w}=$ host wall. A, Phytophthora palmivora disrupts the plasma membrane of sour orange. B, Disruption of the plasma membrane absent for Phytophthora palmivora on trifoliate orange. 
they readily germinated and entered through these sites. Broadbent (5) also observed zoospores of $P$. citrophthora to be attracted similarly toward root wounds in resistant and susceptible citrus hosts. Other fungal species have been observed to penetrate through points where lateral roots emerge or through natural openings $(24,28)$.

In the early stages of infection of young root tips, the mode of penetration of the hypodermis and cellular response of sour orange and trifoliate orange were indistinguishable. This nonspecific interaction of $P$. nicotianae and $P$. palmivora with young roots of susceptible and resistant hosts is in common with other pathosystems involving Phytophthora spp. $(2,5,6,37,38)$. For example, no differences in early responses of susceptible and resistant citrus hosts infected for $P$. citrophthora were noted (5).

Based on cytological observations, it was not possible to conclude whether the mode penetration of citrus root cells by the Phy- tophthora spp. was enzymatic or mechanical. Swollen germ tubes observed at the point of penetration may represent an appressoriumlike structure, such as that observed on roots of bentgrass (Agrostis palustris) inoculated with zoospores of Pythium aphanidermatum (21). Swollen germ tubes were also observed for P. cinnamomi (6) and $P$. megasperma pathosystems (2). Lazarovits et al. (22) and Broadbent (5) called these structures appressoria. However, BeagleRistaino and Rissler (2) were reluctant to refer to them as appressoria, because adherence to the host cell wall was not investigated. If these structures are appressoria, penetration of the host by mechanical action should be indicated. Electron microscopy of citrus roots did not reveal an obvious disruption in the cell wall at the point of penetration. This might, as other workers have concluded $(3,17)$, indicate that enzymatic activity rather than the mechanical action of an appressorium was responsible for penetration.

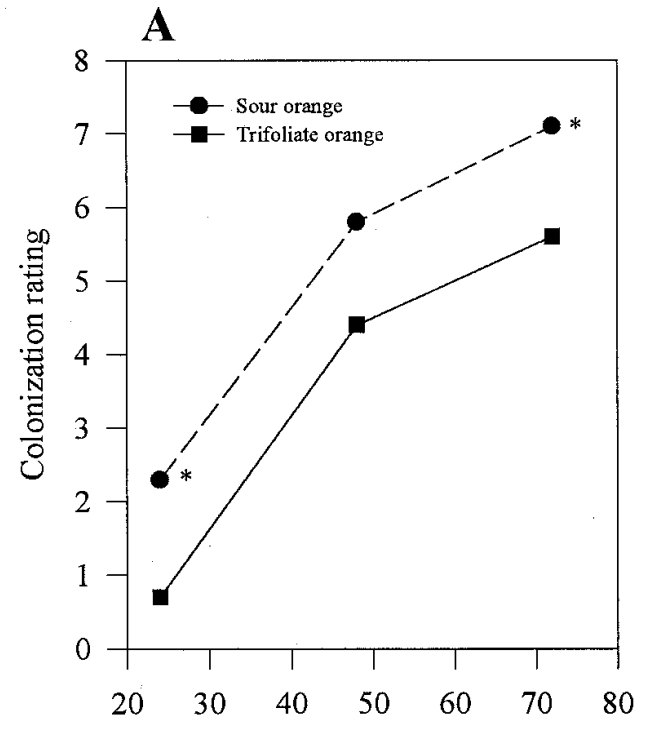

Time (hours)

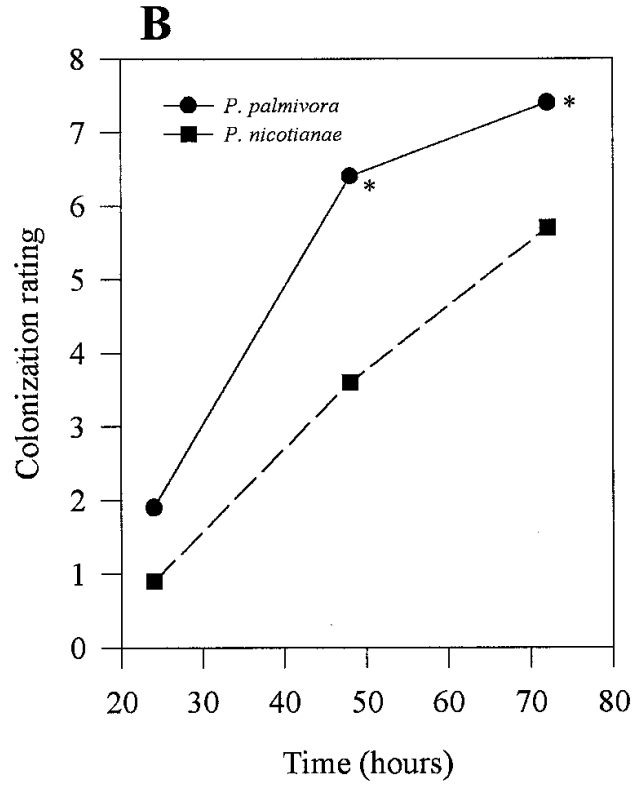

Time (hours)
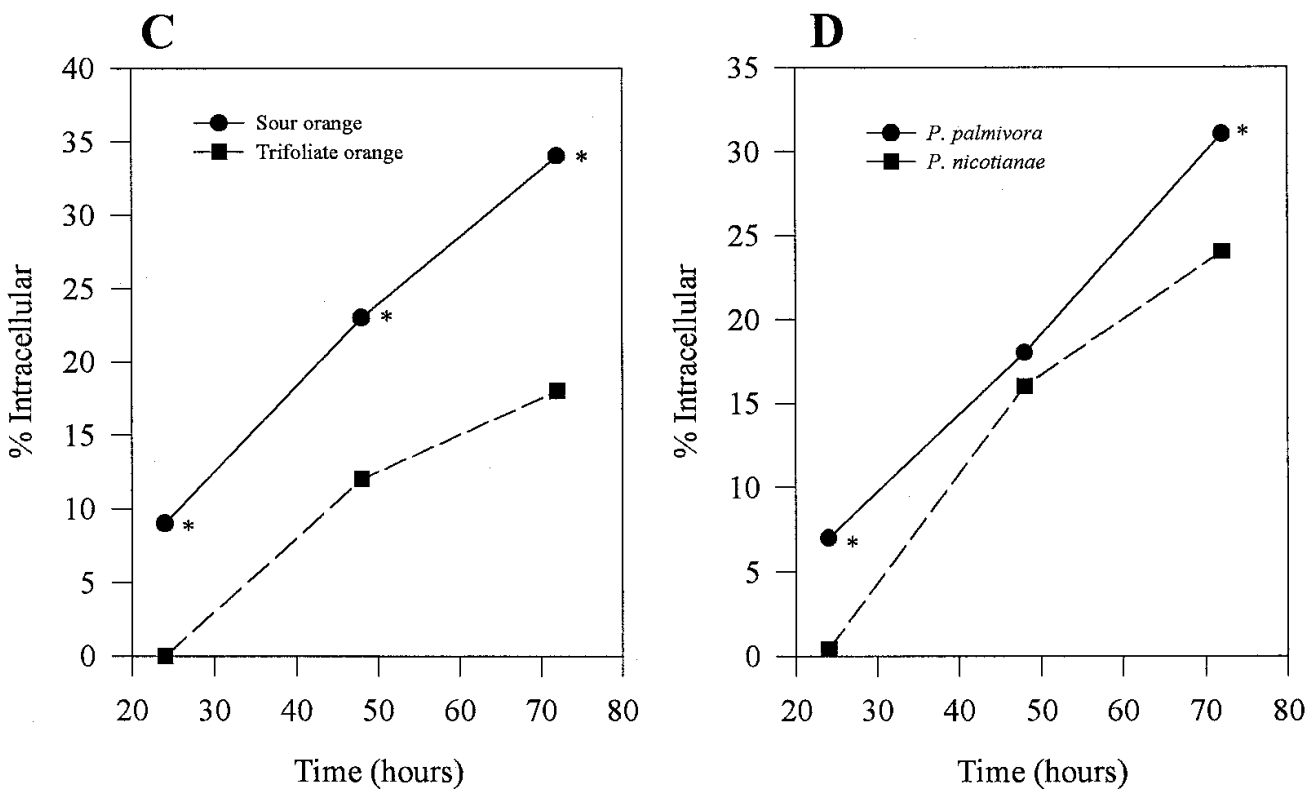

Fig. 5. Inter- and intracellular colonization of Phytophthora nicotianae or P. palmivora hyphae into the cortex of susceptible sour orange (Citrus aurantium) and tolerant trifoliate orange (Poncirus trifoliata) over time. A, Colonization rating for Phytophthora spp. in the cortex of sour orange or trifoliate orange. B, Colonization rating for $P$. nicotianae or P. palmivora in the two hosts. C, Percentage of total hyphae of Phytophthora spp. that were intracellular in the cortex of sour orange or trifoliate orange. D, Percentage of total P. nicotianae or P. palmivora hyphae that were intracellular in the two hosts. An asterisk $(*)$ denotes significant difference $(P \leq 0.05)$ for that specific time interval according to Student's paired $t$ test. 
Penetration of citrus roots occurred between anticlinal walls or through periclinal walls of the hypodermis for both citrus hosts and did not differ between Phytophthora spp. Stössel et al. (34) observed that penetration of soybean (Glycine max) between anticlinal walls or through periclinal walls by two races of Phytophthora sojae (synonym $=P$. megasperma var. sojae) was a characteristic of each race and was not influenced by the host compatibility of the interaction. In another study, $P$. sojae (synonym $=P$. megasperma f. sp. glycinea) penetrated the anticlinal walls of soybean roots $94 \%$ of the time (2).

Cellular response to penetration, 1 to $4 \mathrm{~h}$ after inoculation, did not differ among the citrus pathosystems. When initial penetration occurred, the host cell plasma membrane was disrupted, but the adjacent cells did not appear to be affected. Ward et al. (38) found that in incompatible interactions of $P$. sojae on soybean, all epidermal cells in contact with hyphae were dead within 2 to $3 \mathrm{~h}$ following inoculation, and that a majority of cells associated with, and in the vicinity of, hyphae were dead. Compatible interactions showed less cell damage initially, even when the cells were penetrated. Slusher et al. (31), however, observed no evidence of soybean cell necrosis in advance of $P$. sojae hyphae.

When young citrus roots of tolerant and susceptible rootstocks were evaluated in the greenhouse or the orchard for fungal infection and root rot, few differences were noted $(12,13)$. However, as roots aged, differences in root regeneration and reproduction of the fungus in the rhizosphere developed between tolerant and susceptible rootstocks $(9,13)$. In the current study, regardless of the Phytophthora species, susceptible sour orange had a higher colonization rating and percentage of intracellular hyphae in the cortex than tolerant trifoliate orange at most observation times up to 168 $\mathrm{h}$ after inoculation of roots. Comparing compatible and incompatible races of $P$. sojae on soybean hypocotyls, Stössel et al. (33) determined that the compatible race produced intracellular haustoria more frequently than did the incompatible race. Our findings support those of Graham (13), who suggested that resistance is ex-

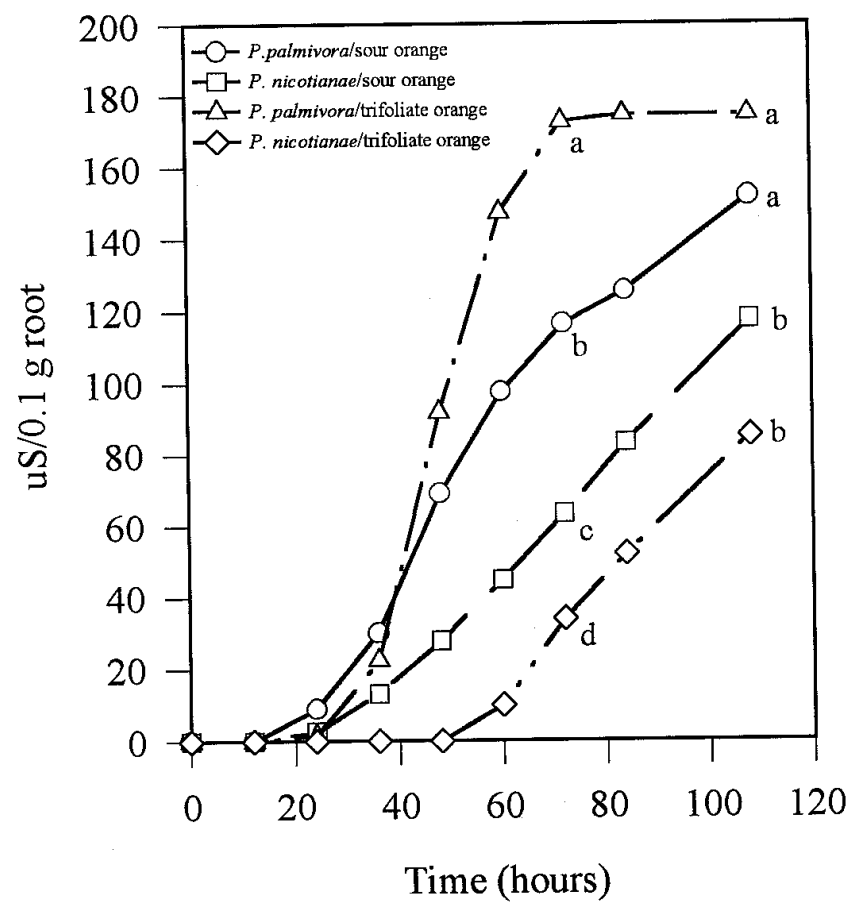

Fig. 6. Electrical conductivity ( $\mu \mathrm{S}$ per $0.1 \mathrm{~g}$ of fresh root weight) of suspensions of root tips of susceptible sour orange (Citrus aurantium) or tolerant trifoliate orange (Poncirus trifoliata) inoculated with motile zoospores of Phytophthora nicotianae or Phytophthora palmivora. Data are means of 10 replications. Points at a specific time interval followed by the same letter are not significantly different $(P \leq 0.05)$ according to least significant differences. pressed in trifoliate orange as reduction in root rot and conversion of infection to propagules of $P$. nicotianae as roots matured. The current study of root infection at the cellular level is also consistent with the finding of Zitko and Timmer (43) that $P$. palmivora is a more aggressive pathogen than $P$. nicotianae on susceptible citrus hosts. $P$. palmivora colonized and disrupted cortical cells of tolerant and susceptible hosts more rapidly after initial infection than $P$. nicotianae, although the rate of development of cellular damage in trifoliate orange was much lower than in sour orange.

Differential colonization and cellular reactions to $P$. nicotianae and $P$. palmivora on sour orange and trifoliate orange are supported by the electrolyte leakage from root tips. Detectable amounts of electrolytes were observed after $24 \mathrm{~h}$ only in roots of sour orange infected with $P$. palmivora. Coincidentally, this was the pathosystem for which disruption of the cells adjacent to the intercellular hyphae was observed at $24 \mathrm{~h}$ after inoculation. Other studies involving Phytophthora spp. showed analogous results within the same time frame. Hanchey and Wheeler (15) observed severe cellular disruption of susceptible tobacco roots as early as $3 \mathrm{~h}$ after inoculated with $P$. nicotianae. Infected cells showed a separation of the plasmalemma from the cell wall, rudimentary dictyosomes, dilated endoplasmic reticulum, and a decreased electron density of the cytoplasm. Protoplasmic shrinkage was also observed in eucalypts $24 \mathrm{~h}$ after infection by $P$. cinnamomi (37), in corn infected by $P$. cinnamomi (39), in soybean infected by $P$. sojae (38), and in susceptible potato cultivars infected by $P$. infestans (17). In the current study, all host-pathogen systems showed cell disruption after $48 \mathrm{~h}$. However, in roots of trifoliate orange infected with $P$. nicotianae, no electrolytes were detected at this time after inoculation. This might be explained by the lower colonization rating in this pathosystem and the lower percentage of intracellular hyphae.

Most cortical cells of both hosts in the vicinity of hyphae collapsed by $72 \mathrm{~h}$ after inoculation with $P$. nicotianae or P. palmivora. The roots of trifoliate orange colonized by $P$. palmivora had a higher electrolyte leakage after $72 \mathrm{~h}$ than trifoliate orange colonized by $P$. nicotianae, probably because $P$. palmivora had a higher colonization rating. The higher conductivity observed in the $P$. palmivora-trifoliate orange system compared with that in either host colonized by $P$. nicotianae was attributable to a higher concentration of electrolytes in roots of trifoliate orange than those of sour orange. Electrolyte leakage from sour orange roots infected with P. palmivora was greater than the leakage from roots of sour orange or trifoliate orange colonized by $P$. nicotianae, because colonization was higher in the $P$. palmivora-sour orange pathosystem. Likewise, roots of sour orange colonized by $P$. nicotianae had a higher rate of electrolyte leakage than roots of trifoliate orange infected with this pathogen. Zilberstein and Pinkas (42) used electrolyte leakage to screen avocado rootstocks for resistance to Phytophthora root rot. However, such a test does not appear to be promising for identification of resistance or tolerance in citrus rootstocks because of differences in cell electrolyte concentrations among hosts.

The disruption of the cells adjacent to the intercellular hyphae suggests the production of a toxin(s) by the pathogens. Necrosis of host tissue has been observed for other Phytophthora pathosystems $(6,37,38)$, and toxins have been isolated in culture from several Phytophthora spp. $(1,4,14,19,25,35)$. However, necrosis in advance of contact with hyphae was not observed in soybean rootlets infected with $P$. sojae (31) nor in our study. Collapse only of cells immediately adjacent to hyphae in both the tolerant and susceptible citrus hosts suggested that this was not a hypersensitive response. Cell collapse adjacent to hyphae was also noted by Tippet et al. (37) for infection of eucalypt roots by $P$. cinnamomi.

This study established no differences in the initial infection of roots of susceptible and tolerant hosts. The differential response was after penetration of the hypodermis and during colonization of cortical cells. Although cellular responses unique to a resistant host, such as callose formation or hypersensitivity, were not ob- 
served in the cortex, there was lower inter- and intracellular colonization of trifoliate orange compared with sour orange by both pathogens. This leads to the conclusion that a putative resistance factor(s) in the trifoliate orange roots inhibited the growth of Phytophthora spp. Further studies are needed to identify the factor(s) and establish whether it is constitutive in root tissues or is expressed either locally or systemically after infection. This information may contribute to improved root rot-resistance in citrus through breeding, including transformation of genes for the factor(s) into current rootstocks.

\section{ACKNOWLEDGMENTS}

Florida Agricultural Experiment Station journal series no. R-06174. T. L. Widmer was supported by a Hunt Brothers Fellowship for completion of this research in partial fulfillment of his Ph.D. degree. We thank D. Achor and C. Davis for their assistance in sample preparation for the electron microscope.

\section{LITERATURE CITED}

1. Ballio, A., Gianani, L., Borrelli, R., Bottalico, A., and Graniti, A. 1972. Production of phytotoxins by Phytophthora parasitica B. de Haan var. nicotianae (Dast.) Waterh. Pages 431-432 in: Phytotoxins in Plant Diseases. R. K. S. Wood, A. Ballio, and A. Graniti, eds. Academic Press, London.

2. Beagle-Ristaino, J. E., and Rissler, J. F. 1983. Histopathology of susceptible and resistant soybean roots inoculated with zoospores of Phytophthora megasperma f. sp. glycinea. Phytopathology 73:590-595.

3. Benhamou, N., and Côté, F. 1992. Ultrastructure and cytochemistry of pectin and cellulose degradation in tobacco roots infected by Phytophthora parasitica var. nicotianae. Phytopathology 82:468-478.

4. Breiman, A., and Barash, I. 1981. Partial characterization of phytotoxic compounds in culture filtrates of Phytophthora citrophthora. Phytopathol. Z. 102:1-9.

5. Broadbent, P. 1969. Observations on the mode of infection of Phytophthora citrophthora in resistant and susceptible citrus roots. Proc. First Int. Citrus Symp. Vol. III:1207-1210.

6. Cahill, D., Legge, N., Grant, B., and Weste, G. 1989. Cellular and histological changes induced by Phytophthora cinnamomi in a group of plant species ranging from fully susceptible to fully resistant. Phytopathology 79:417-424.

7. Cahill, D., and Weste, G. 1983. Formation of callose deposits as a response to infection with Phytophthora cinnamomi. Trans. Br. Mycol. Soc. 80:23-29.

8. Dawes, C. J. 1994. Introduction to Biological Electron Microscopy: Theory and Techniques. Ladd Research Industries, Inc. Burlington, VT.

9. Duncan, L. W., Graham, J. H., and Timmer, L. W. 1993. Seasonal patterns associated with Tylenchulus semipenetrans and Phytophthora parasitica in the citrus rhizosphere. Phytopathology 83:573-581.

10. Ferris, R. S. 1984. Effects of microwave oven treatment on microorganisms in soil. Phytopathology 74:121-126.

11. Freytag, S., Arabatzis, N., Hahlbrock, K., and Schmelzer, E. 1994. Reversible cytoplasmic rearrangements precede wall apposition, hypersensitive cell death and defense-related gene activation in potato/Phytophthora infestans interactions. Planta 194:123-135.

12. Graham, J. H. 1990. Evaluation of tolerance of citrus rootstocks to Phytophthora root rot in chlamydospore-infested soil. Plant Dis.74:743-746.

13. Graham, J. H. 1995. Root regeneration and tolerance of citrus rootstocks to root rot caused by Phytophthora nicotianae. Phytopathology 85:111-117.

14. Graniti, A. 1969. Host-parasite relations in citrus diseases as exemplified by Phytophthora gummosis and Deuterophoma 'mal seco'. Proc. First Int. Citrus Symp. Vol. III:1187-2110.

15. Hanchey, P., and Wheeler, H. 1971. Pathological changes in ultrastructure: Tobacco roots infected with Phytophthora parasitica var. nicotianae. Phytopathology 64:834-840.

16. Hinch, J. M., Wetherbee, R., Mallet, J. E., and Clarke, A. E. 1985. Response of Zea mays roots to infection with Phytophthora cinnamomi. I. The epidermal layer. Protoplasma 126:178-187.

17. Hohl, H. R., and Suter, E. 1976. Host-parasite interfaces in a resistant and a susceptible cultivar of Solanum tuberosum inoculated with Phytophthora infestans: Leaf tissue. Can. J. Bot. 54:1956-1970.

18. Humphrey, C. D., and Pittman, F. E. 1974. A simple methylene blueazure II-basic fuchsin stain for epoxy-embedded tissue sections. Stain Technol. 49:9-14.

19. Keenan, P., Bryan, I. B., and Friend, J. 1985. The elicitation of the hypersensitive response of potato tuber tissue by a component of the culture filtrate of Phytophthora infestans. Physiol. Plant Pathol. 26:343-355.

20. Kosola, K. R., Eissenstat, D. M., and Graham, J. H. 1995. Root demog- raphy of mature citrus trees: the influence of Phytophthora nicotianae. Plant Soil 171:283-288.

21. Kraft, J. M., Endo, R. M., and Erwin, D. C. 1967. Infection of primary roots of bentgrass by zoospores of Pythium aphanidermatum. Phytopathology 57:86-90.

22. Lazarovits, G., Stössel, R., and Ward, E. W. B. 1981. Age-related changes in specificity and glyceollin production in the hypocotyl reaction of soybeans to Phytophthora megasperma var. sojae. Phytopathology 71:94-97.

23. Mitchell, D. J., and Kannwischer-Mitchell, M. E. 1992. Phytophthora. Pages 31-38 in: Methods for Research on Soilborne Phytopathogenic Fungi. L. L. Singleton, J. D. Mihail, and C. M. Rush, eds. The American Phytopathological Society, St. Paul, MN.

24. Nemec, S., Stamper Achor, D., and Albrigo, L. G. 1986. Microscopy of Fusarium solani infected rough lemon citrus fibrous roots. Can. J. Bot. 64:2840-2847.

25. Paxton, J. D. 1972. Toxin production by Phytophthora megasperma Drechsl. var. sojae Hild. Page 433 in: Phytotoxins in Plant Diseases. R. K. S. Wood, A. Ballio, and A. Graniti, eds. Academic Press, London.

26. Philips, D. R. 1993. Pathological anatomy of root diseases caused by Phytophthora species. Pages 205-235 in: Handbook of Cytology, Histology, and Histochemistry of Fruit Tree Diseases. A. R. Biggs, ed. CRC Press, Boca Raton, FL.

27. Reynolds, E. S. 1963. The use of lead citrate at high $\mathrm{pH}$ as an electronopaque stain in EM. J. Cell Biol. 17:208.

28. Sadasivan, T. S., and Subramanian, C. V. 1960. Interaction of pathogen, soil, other microorganisms in the soil, and host. Pages 273-313 in: Plant Pathology: An Advanced Treatise, Vol. 2. J. G. Horsfall and A. E. Dimond, eds. Academic Press, New York.

29. Sandler, H. A., Timmer, L. W., Graham, J. H., and Zitko, S. E. 1989. Effect of fungicide applications on populations of Phytophthora parasitica and on feeder root densities and fruit yields of citrus trees. Plant Dis. 73:902-906.

30. Singleton, L. L., Mihail, J. D., and Rush, C. M. 1992. Methods for Research on Soilborne Phytopathogenic Fungi. The American Phytopathological Society, St. Paul, MN.

31. Slusher, R. L., Haas, D. L., Carothers, Z. B., and Sinclair, J. B. 1974. Ultrastructure at the host-parasite interface of Phytophthora megasperma var. sojae in soybean rootlets. Phytopathology 64:834-840.

32. Stempack, J. C., and Ward, R. T. 1964. An improved staining method for electron microscopy. J. Cell Biol. 22:697-701.

33. Stössel, P., Lazarovits, G., and Ward, E. W. B. 1980. Penetration and growth of compatible and incompatible races of Phytophthora megasperma var. sojae in soybean hypocotyl tissues differing in age. Can. J. Bot. 58:2594-2601.

34. Stössel, P., Lazarovits, G., and Ward, E. W. B. 1981. Differences in the mode of penetration of soybean hypocotyls by two races of Phytophthora megasperma var. sojae. Can. J. Bot. 59:1117-1119.

35. Strange, R. N., Piippard, D. J., and Strobel, G. A. 1982. A protoplast assay for phytotoxic metabolites produced by Phytophthora drechsleri in culture. Physiol. Plant Pathol. 20:359-364.

36. Tippett, J. T., Holland, A. A., Marks, G. C., and O'Brien, T. P. 1976. Penetration of Phytophthora cinnamomi into disease tolerant and susceptible eucalypts. Arch. Microbiol. 108:231-242.

37. Tippett, J. T., O'Brien, T. P., and Holland, A. A. 1977. Ultrastructural changes in eucalypt roots caused by Phytophthora cinnamomi. Physiol. Plant Pathol. 11:279-286.

38. Ward, E. W. B., Cahill, D. M., and Bhattacharyya, M. K. 1989. Early cytological differences between compatible and incompatible interactions of soybeans with Phytophthora megasperma f. sp. glycinea. Physiol. Mol. Plant Pathol. 34:267-283.

39. Wetherbee, R., Hinch, J. M., Bonig, I., and Clarke, A. E. 1985. Response of Zea mays roots in infection with Phytophthora cinnamomi. II. The cortex and stele. Protoplasma 126:188-197.

40. Widmer, T. L. 1996. Effect of composted municipal waste on infection of citrus by Phytophthora nicotianae and the infection of citrus roots by Phytophthora spp. Ph.D. dissertation. University of Florida, Gainesville.

41. Wolf, D. C., and Skipper, H. D. 1994. Soil sterilization. Pages 41-51 in: Methods of Soil Analysis. Part 2. Microbiological and Biochemical Properties. R. W. Weaver, S. Angle, P. Bottomley, D. Bezdicek, S. Smith, A. Tabatabai, and A. Wollum, eds. Soil Science Society of America, Inc., Madison, WI.

42. Zilberstein, M., and Pinkas, Y. 1987. Detached root inoculation-A new method to evaluate resistance to Phytophthora root rot in avocado trees. Phytopathology 77:841-844.

43. Zitko, S. E., and Timmer, L. W. 1994. Competitive parasitic abilities of Phytophthora parasitica and P. palmivora on fibrous roots of citrus. Phytopathology 84:1000-1004.

44. Zitko, S. E., Timmer, L. W., and Sandler, H. A. 1991. Isolation of Phytophthora palmivora pathogenic to citrus in Florida. Plant Dis. 75:532-535. 